Arq. Bras. Med. Vet. Zootec., v.56, n.6, p.757-763, 2004

\title{
Efeito do acipin sobre a degradabilidade e taxa de passagem de silagens de capim-elefante e de milho, em bovinos Holandês $\times$ Zebu
}

\author{
[Effect of acipin on the degradability and rate of passage of elephant-grass and corn silages \\ in Holstein $\times$ Zebu cattle] \\ ${ }^{1}$ Doutorando em Produção Animal - CCTA-UENF \\ ${ }^{2}$ Centro de Ciências e Tecnologias Agropecuárias - Universidade Estadual do Norte Fluminense \\ Avenida Alberto Lamego, 2000, \\ 28013-600 - Campos dos Goytacazes, RJ \\ ${ }^{3}$ Embrapa Semi-Árido - Petrolina, PE \\ ${ }^{4}$ Universidade Federal de Viçosa - Viçosa, MG \\ ${ }^{5}$ Bolsista do CNPq
}

\begin{abstract}
RESUMO
Avaliou-se o efeito da inclusão de acipin nas silagens de capim-elefante e de milho sobre a taxa de passagem das fases sólida e líquida da digesta ruminal e sobre a degradabilidade da matéria seca (MS), proteína bruta $(\mathrm{PB})$ e fibra em detergente neutro (FDN), em quatro bovinos. Os animais, com média de peso de $550 \mathrm{~kg}$, foram confinados em baias individuais por 90 dias. O experimento foi conduzido em quatro períodos experimentais, seguindo um esquema de parcelas subdivididas, tendo nas parcelas um esquema fatorial $2 \times 2$ (duas silagens combinadas com ausência e presença de acipin) e nas subparcelas o tempo de coleta de líquido ruminal, em delineamento inteiramente ao acaso com quatro repetições. A degradabilidade efetiva da MS, da PB e da FDN da silagem de capim-elefante sem adição de acipin foi menor do que a das silagens de capim-elefante com acipin, de milho sem acipin e de milho com acipin; estas foram semelhantes entre si. A taxa de passagem de sólidos ruminais foi maior nos animais que consumiram silagem de milho. A taxa de passagem de líquidos foi maior nos animais que consumiram silagem de capim-elefante. A inclusão de acipin melhorou a degradabilidade da MS, da PB e da FDN da silagem de capim-elefante.
\end{abstract}

Palavras-chave: consumo potencial, digestibilidade, fermentação ruminal, valor nutritivo

\begin{abstract}
The effects of adding acipin to elephantgrass and corn silages on the passage rates of the solid and liquid phases of the ruminal digesta, and on degradabilities of dry matter (DM), crude protein $(C P)$ and neutral detergent fiber $(N D F)$ were evaluated. The animals with average live weight of $550 \mathrm{~kg}$, were kept in individual stalls for 90 days. The experiment was carried out in four experimental periods, according to a split plot arrangement, with $2 \times 2$ (two silages combined with absence or presence of acipin) factorial treatment combination in the plot and the time of collection of ruminal liquid in the split plot, in a completely randomized design with four replicates. The degradabilities of DM, CP and NDF in the elephantgrass silage without acipin was lower as compared to elephantgrass silage with acipin and to corn silage with or without acipin, that were similar. The passage rates of the ruminal solids were higher
\end{abstract}

Recebido para publicação em 23 de junho de 2003

Recebido para publicação, após modificações, em 19 de abril de 2004

Apoio financeiro: FENORTE

* Autor para correspondência

E-mail: lara@uenf.br 
in animals fed on corn silage, and the ruminal liquid passage rates were higher in animals fed on elephantgrass silage. The addition of acipin improved the degradability of DM, CP and NDF of elephantgrass silage.

Keywords: digestibility, nutritive value, potential intake, rumen fermentation

\section{INTRODUÇÃO}

A avaliação dos alimentos visa predizer suas características físicas, químicas e morfológicas, bem como seu comportamento no trato digestivo dos animais, caracterizando o quanto podem influir na degradação e na taxa de passagem da digesta. Ørskov e McDonald (1979) constataram que a taxa de remoção da digesta ruminal influencia a extensão da degradação dos alimentos, conseqüentemente, a digestibilidade in vivo da dieta e a síntese de proteína microbiana. Com essa avaliação pode-se estimar com maior precisão o consumo potencial de forragens, pois segundo Waldo e Jorgensen (1981), o consumo de matéria seca (MS) é a variável mais importante que influi no desempenho animal, sendo regulado por mecanismos que ocorrem a curto e a longo prazos (Mertens, 1987).

O consumo de silagem ad libitum pelos ruminantes é geralmente menor que o consumo de feno, mesmo que ela contenha teores similares de fibra em detergente neutro (FDN) e digestibilidade (McDonald, 1981). Em virtude de pouca regularidade da disponibilidade de forragem ao longo do ano, a silagem tem sido utilizada como instrumento auxiliar na manutenção e ampliação da produção animal, disponibilizando alimento principalmente ao longo do período de escassez (Nussio, 1995).

As silagens de capim-elefante e milho são amplamente utilizadas na alimentação de ruminantes, podendo estar associadas a aditivos que possibilitem melhorar o seu valor nutritivo. Dentre os vários fatores que determinam a qualidade da silagem, o processo de fermentação que ocorre no silo pode ser considerado de importância. Durante esse processo, os carboidratos solúveis são convertidos em ácidos orgânicos, como o ácido lático, que por apresentar alta constante de dissociação é responsável pela queda do $\mathrm{pH}$ e inibição da atividade de bactérias do gênero Clostridium
(Vilela, 1998), que são indesejáveis por causarem deterioração da silagem.

$\mathrm{Na}$ indústria alimentícia o ácido lático é utilizado por apresentar propriedades acidulante, regulador de $\mathrm{pH}$ e anti-microbiana dentre outras. Em razão da sua origem biotecnológica, também apresenta efeito sinergético com anti-oxidantes, é potencializador do sabor do alimento e é higroscópico (Purac, 1998).

A empresa Purac Sínteses produz o ácido lático polimerizado residual (Acipin), que é obtido no processo de purificação do ácido lático (aditivo alimentício) a partir da fermentação da sacarose (açúcar de cana-de-açúcar) por bactérias láticas (Lactobacillus). O acipin é subproduto marrom, de aspecto líquido viscoso, com teor de matéria seca entre 70 a $85 \%$ e acidez total entre 55 e $75 \%$. Sua aplicação, segundo a empresa, é especialmente indicada na alimentação animal.

O objetivo deste trabalho foi avaliar o efeito da inclusão de acipin às silagens de capim-elefante e de milho sobre a taxa de passagem das fases sólida e líquida da digesta ruminal e sobre a degradabilidade efetiva da matéria seca, da proteína bruta e da fibra em detergente neutro, em bovinos em regime de mantença.

\section{MATERIAL E MÉTODOS}

Foram utilizados bovinos machos castrados adultos, mestiços Holandês $\times$ Zebu, com peso vivo médio de $550 \mathrm{~kg}$, fistulados no rúmen, alimentados ad libitum com silagem de capimelefante (Pennisetum purpureum, Schum.) ou silagem de milho (Zea mays, L.), em presença ou ausência de acipin. Os tratamentos consistiram da combinação de dois tipos de silagem e inclusão ou não de acipin, assim descritos: 1) silagem de capim-elefante sem acipin, 2) silagem de capim-elefante com acipin, 3) silagem de milho com acipin e 4) silagem de milho sem acipin. $\mathrm{O}$ acipin foi adicionado durante a confecção da silagem na proporção de $4,8 \%$ na 
matéria natural (MN). A composição das silagens encontra-se na Tab. 1.

Tabela 1. Teores de matéria seca (MS), proteína bruta (PB) e fibra em detergente neutro (FDN) das silagens de capim-elefante e milho

\begin{tabular}{lccc}
\hline & Acipin & $\begin{array}{c}\text { Silagem de } \\
\text { capim-elefante }\end{array}$ & $\begin{array}{c}\text { Silagem } \\
\text { de milho }\end{array}$ \\
\hline \multirow{2}{*}{ MS, \% } & Presença & 35,62 & 33,97 \\
& Ausência & 33,97 & 30,90 \\
\multirow{2}{*}{ PB, \% da MS } & Presença & 5,91 & 8,18 \\
& Ausência & 5,73 & 7,11 \\
\multirow{2}{*}{ FDN, \% da MS } & Presença & 66,72 & 57,87 \\
& Ausência & 68,98 & 63,06 \\
\hline
\end{tabular}

Para estimar a taxa de passagem da digesta pelo rúmen foram utilizadas as metodologias dos indicadores externos, um para a fase líquida (cobalto-EDTA) e outro para fase sólida (cromo mordante). Para o preparo do complexo CoEDTA, seguiu-se a metodologia descrita por Udén et al. (1980). O fornecimento do Co-EDTA foi feito em dose única de $5 \mathrm{~g}$, e a fibra mordantada foi colocada diretamente no rúmen via fístula ruminal, na quantidade de $100 \mathrm{~g}$ por animal. As amostras de sólidos e líquidos ruminais respeitaram os tempos de coleta de 0 (antes de colocar os indicadores no rúmen) e 2, $4,8,12,24,36$ e 48 horas após a colocação dos indicadores no rúmen.

Para o cálculo da taxa de passagem da matéria seca da digesta e tempo de retenção da digesta no rúmen pelo modelo unicompartimental, foi utilizado o modelo de Czerkawski (1986):

$Y=a e^{-k t}$, em que

Y é a concentração do indicador no tempo t; $k$ representa a taxa de passagem no rúmen $\left(\mathrm{h}^{-1}\right), \mathrm{t}$ é o tempo de amostragem do indicador (h), a é a concentração do indicador em $\mathrm{t}=0$, pressupondo mixagem instantânea ao conteúdo ruminal (ppm); e é a base do logarítimo neperiano.
As estimativas da degradabilidade in situ das silagens foram obtidas de acordo com a metodologia descrita por Mehrez e Ørskov (1977), seguindo os tempos de incubação no rúmen de $0,3,6,12,24,48$ e 72 horas. Foram incubadas $5 \mathrm{~g}$ de amostras em sacos de náilon de tamanho $22 \times 9,7 \mathrm{~cm}$ com porosidade de $50 \mu \mathrm{m}$. Os dados sobre o desaparecimento da MS, PB e FDN nos diferentes tempos de incubação foram ajustados ao modelo descrito por Ørskov e McDonald (1979), $Y=a+b\left(1-e^{-c t}\right)$. A obtenção da degradabilidade efetiva (DE) foi calculada por intermédio da função matemática $D E=a+(b c) / c+k$.

As amostras incubadas no rúmen foram analisadas quanto ao teor de matéria seca, proteína bruta e fibra em detergente neutro, de acordo com metodologia citada por Silva (1990). $\mathrm{O}$ teor de cromo foi determinado pelo método proposto por Kimura e Miller (1967), e o de cobalto por espectrofotometria de absorção atômica.

As taxas de passagem de líquidos e sólidos e a degradabilidade foram analisadas conforme delineamento experimental inteiramente ao acaso, em esquema de parcelas subdivididas, tendo nas parcelas os tratamentos, constituídos de fatorial $2 \times 2$ (duas silagens combinadas com presença e ausência de acipin), e nas subparcelas o período de coleta: $0,3,6,12,24,48$ e 72 horas após a incubação, para a variável degradabilidade, e $0,2,4,6,12,24,36$ e 48 horas após o fornecimento do indicador para a variável taxa de passagem. As análises de variância foram realizadas, e as médias dos tratamentos foram comparadas utilizando-se o teste Tukey ao nível de $5 \%$ de probabilidade. $\mathrm{O}$ seguinte modelo estatístico foi utilizado na análise:

$\mathrm{Y}_{\mathrm{ijrk}}=\mu+\mathrm{F}_{\mathrm{i}}+\mathrm{A}_{\mathrm{j}}+\mathrm{FA}_{\mathrm{ij}}+\mathrm{e}_{\mathrm{ijr}}+\mathrm{P}_{\mathrm{k}}+\mathrm{FP}_{\mathrm{ik}}+\mathrm{AP}_{\mathrm{jk}}+\mathrm{FAP}_{\mathrm{ijk}}+\mathrm{e}_{\mathrm{ijrk}}$, em que

$\mathrm{Y}_{\mathrm{ijrk}}=$ observação geral relativa ao animal $r$, da silagem $i$, do acipin $j$ e do período de coleta $\mathrm{k}$; $\mu=$ constante geral; $F_{i}=$ efeito do tipo silagem $(1,2) ; \mathrm{A}_{\mathrm{j}}=$ efeito do acipin $(1,2) ; \mathrm{FA}_{\mathrm{ij}}=$ efeito da interação de tipo de silagem e acipin; $\mathrm{e}_{\mathrm{ijr}}=$ erro associado à parcela; $\mathrm{P}_{\mathrm{k}}=$ efeito do período de coleta das amostras ruminais; $\mathrm{FP}_{\mathrm{ik}}=$ efeito da interação de tipo de silagem e intervalos de coleta; $\mathrm{AP}_{\mathrm{jk}}=$ efeito da interação de acipin e intervalo de coleta; $\mathrm{FAP}_{\mathrm{ijk}}=$ efeito da interação do tipo de silagem, acipin e o intervalo de coleta; $\mathrm{e}_{\mathrm{ijk}}=$ erro devido ao acaso. 


\section{RESULTADOS E DISCUSSÃO}

O consumo de matéria seca (CMS) de silagem de milho foi $86,8 \%(\mathrm{P}<0,05)$, maior do que o CMS da silagem de capim-elefante (Tab. 2), o que refletiu diretamente em aumento da taxa de passagem de sólidos nos animais alimentados com silagem de milho. De acordo com Colucci et al. (1990), a taxa de passagem de partículas pelo rúmen aumenta à medida que o consumo de matéria seca se eleva.

Tabela 2. Consumo médio ( $\%$ do peso vivo) de matéria seca $(\mathrm{CMS})$, proteína bruta $(\mathrm{CPB})$ e fibra em detergente neutro (CFDN) por bovinos mestiços Holandês $\times$ Zebu

\begin{tabular}{|c|c|c|c|c|c|}
\hline & Acipin & $\begin{array}{c}\text { Silagem de } \\
\text { capim-elefante }\end{array}$ & $\begin{array}{l}\text { Silagem } \\
\text { de milho }\end{array}$ & Média & $\mathrm{CV}(\%)$ \\
\hline \multirow{3}{*}{ CMS } & Presença & 1,22 & 1,94 & $1,58 \mathrm{~A}$ & \multirow[t]{3}{*}{20,90} \\
\hline & Ausência & 1,05 & 2,32 & $1,69 \mathrm{~A}$ & \\
\hline & Média $^{1}$ & $1,14 \mathrm{~b}$ & $2,13 a$ & & \\
\hline \multirow{3}{*}{$\mathrm{CPB}$} & Presença & 0,07 & 0,16 & $0,12 \mathrm{~A}$ & \multirow[t]{3}{*}{22,62} \\
\hline & Ausência & 0,06 & 0,16 & $0,11 \mathrm{~A}$ & \\
\hline & Média $^{1}$ & $0,07 \mathrm{~b}$ & $0,16 \mathrm{a}$ & & \\
\hline \multirow{3}{*}{ CFDN } & Presença & $0,79 \mathrm{aA}$ & $1,13 \mathrm{aA}$ & 0,96 & \multirow[t]{3}{*}{9,81} \\
\hline & Ausência & $0,73 \mathrm{bA}$ & $1,43 \mathrm{aA}$ & 1,08 & \\
\hline & Média $^{1}$ & 0,76 & 1,28 & & \\
\hline
\end{tabular}

${ }^{1}$ Médias na linha/coluna seguidas de $\overline{\text { letras }} \overline{\text { distintas }}$ minúsculas/maiúsculas diferem entre si pelo teste Tukey $(\mathrm{P}<0,05)$.

As taxas de passagem de sólidos ruminais e o tempo de retenção da matéria seca obtidos pelo modelo unicompartimental encontram-se no Tab. 3. A taxa de passagem de sólidos ruminais foi maior nos animais que consumiram silagem de milho.

Tabela 3. Estimativa da taxa de passagem de sólidos para os diferentes tratamentos e tempo médio de retenção ruminal em bovinos mestiços Holandês $\times$ Zebu

\begin{tabular}{cccc}
\hline & Acipin & $\begin{array}{c}\text { Silagem de } \\
\text { capim-elefante }\end{array}$ & $\begin{array}{c}\text { Silagem } \\
\text { de milho }\end{array}$ \\
\hline $\begin{array}{c}\text { Taxa de passagem } \\
(\% / \mathrm{h})\end{array}$ & Presença & 1,51 & 2,68 \\
Ausência & 1,08 & 2,81 \\
Tempo de retenção & Presença & 66,23 & 37,31 \\
$(\mathrm{~h})$ & Ausência & 92,59 & 35,59 \\
\hline
\end{tabular}

A taxa de passagem de sólidos ruminais nos animais alimentados com silagem de capimelefante foi menor do que as relatadas por Gomes (1991), 5,1 e 3,8 (\%/h), ao estudar o feno de capim-elefante (cv napier e cameroom, respectivamente). Hristov e Broderick (1996), ao avaliarem a silagem de milho adicionada de $2,2 \%$ de uréia utilizando itérbio ( $\mathrm{Yb}$ ) como marcador, estimaram taxa de passagem de partículas $(5 \% / \mathrm{h})$ maior do que a estimada nesta pesquisa (Tab. 3), em razão do maior CMS observado por esses autores.

A taxa de passagem das partículas da silagem de capim-elefante foi menor do que o valor descrito pelo Aguicultural... (1984) para animais em regime de mantença, com baixo nível de consumo de matéria seca $(2 \% / \mathrm{h})$.

As taxas de passagem de líquidos ruminais obtidas pelo modelo unicompartimental e o tempo de retenção de líquidos encontram-se na Tab. 4. A taxa de passagem de líquidos ruminais foi maior nos animais que consumiram silagem de capim-elefante.

Tabela 4. Estimativa da taxa de passagem de líquidos para os diferentes tratamentos e tempo médio de retenção ruminal em bovinos mestiços Holandês $\times$ Zebu

\begin{tabular}{cccc}
\hline & Acipin & $\begin{array}{c}\text { Silagem de } \\
\text { capim-elefante }\end{array}$ & $\begin{array}{c}\text { Silagem } \\
\text { de milho }\end{array}$ \\
\hline $\begin{array}{c}\text { Taxa de passagem } \\
(\% / h)\end{array}$ & $\begin{array}{c}\text { Presença } \\
\text { Ausência }\end{array}$ & 8,77 & 4,94 \\
& & & 5,73 \\
Tempo de retenção & $\begin{array}{c}\text { Presença } \\
\text { (h) }\end{array}$ & 11,40 & 20,24 \\
Ausência & 11,46 & 17,86 \\
\hline
\end{tabular}

Segundo Hristov e Broderick (1996), as estimativas da taxa de passagem de líquidos variam em função da dieta fornecida, do sexo, do estado fisiológico do animal e, inclusive, do tipo de indicador utilizado no processo de estimação. Segundo esses autores, para vacas secas alimentadas com 50\% de concentrado na dieta, utilizando-se o Cr-EDTA como marcador, a taxa de passagem de líquidos foi $8 \% / \mathrm{h}$, e para vacas que produziam $28 \mathrm{~kg} / \mathrm{d}$ de leite, $11 \% / \mathrm{h}$. Evidentemente que para animais em regime de mantença, recebendo apenas volumoso e com baixo consumo, os valores devem ser menores, levando-se em consideração todos os aspectos envolvidos na determinação da taxa de passagem, tanto de partículas como de líquidos, pelo rúmen.

As estimativas da degradação das silagens de 
Efeito do acipin sobre a degradabilidade e taxa de passagem de silagens...

capim-elefante encontram-se na Tab. 5. Foram encontrados para a fração solúvel da MS (16,9 e $6,4 \%$ ) valores menores do que os citados por
Tosi et al. (1999), 34,7 e 30,7\%, ao avaliarem silagem de capim-elefante pura e com adição de $20 \%$ de sabugo de milho, respectivamente.

Tabela 5. Fração solúvel (a), fração potencialmente degradável (b), taxa de degradação da fração b (c) e fração não degradável (i) da matéria seca (MS), proteína bruta $(\mathrm{PB})$ e da fibra em detergente neutro (FDN) das silagens

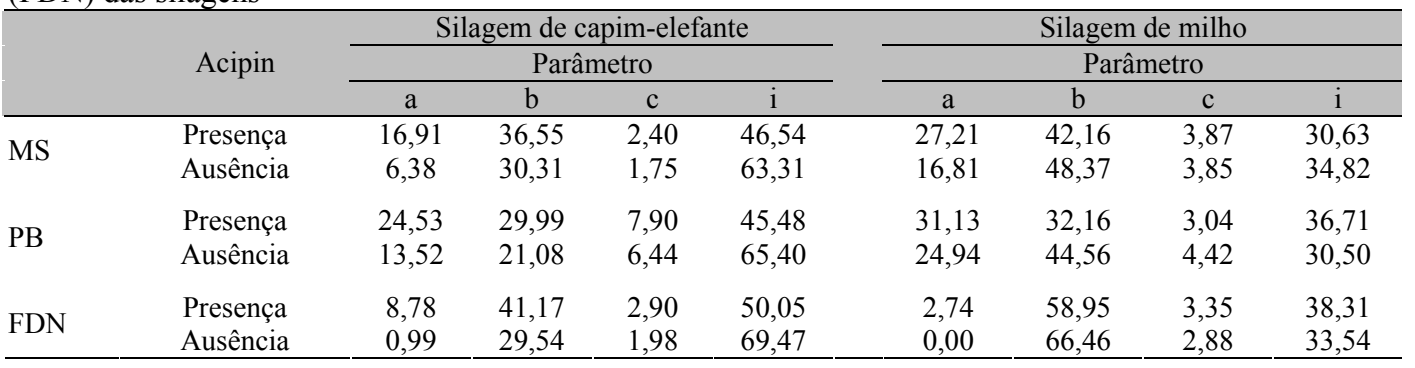

A fração a da PB da silagem de capim-elefante com acipin se apresentou $81,4 \%$ maior do que a da silagem sem acipin, com taxas de degradação da fração b próximas $(7,9$ e $6,4 \% / h)$. A fração a da FDN deveria se apresentar nula ou quase nula, uma vez que sua obtenção é atribuída a erros no processo de estimação. Como essa fração foi relativamente alta, na silagem com acipin esse efeito pode ser atribuído principalmente a ele.

A silagem de capim-elefante com acipin apresentou, respectivamente, valores de MS, de PB e de FDN não degradáveis no rúmen (fração i) $36,0 \%, 43,8 \%$ e $38,8 \%$ menores do que a silagem de capim-elefante sem acipin. As frações da MS não degradável estimadas neste trabalho foram maiores do que as relatadas por Tosi et al. (1999), ao avaliarem silagem de capim-elefante pura $(13,4 \%)$ e silagem de capim-elefante adicionada de $20 \%$ de sabugo de milho (20,0\%). Isto pode ser atribuído ao fato desses autores terem ensilado as forrageiras após 46 dias de crescimento, contra 90 dias neste experimento.

A fração a da MS da silagem de milho sem acipin, 16,8\% (Tab. 5), foi menor do que a relatada por Martins et al. (1999), 45,2\%, para taxa de degradação da fração b, 1,1\%/h, também menor do que a encontrada neste trabalho, $4 \% / \mathrm{h}$, provavelmente em razão do elevado teor de FDN $(63,0 \%)$ estimado para essa silagem, neste experimento (Tab. 1).

A fração a da PB da silagem de milho adicionada de acipin foi $24,8 \%$ maior do que a da silagem sem acipin, com taxas de degradação da fração b próximas (para PB 3,0 e 4,4\%/h e para FDN 3,4 e $2,9 \% / \mathrm{h}$ ). O valor estimado para a fração a da PB da silagem de milho sem acipin $(24,9 \%)$ foi menor do que o estimado por Martins et al. (1999), que utilizaram dieta com 13\% de concentrado (61,5\%), e por Rossi Jr. (1997), que utilizou dieta com $18 \%$ de concentrado (62,6\%), evidenciando que, em animais que receberam dieta exclusiva de silagem, a degradação da fração solúvel é bem menor.

O resíduo não degradável da MS (fração i) da silagem de milho com acipin (30,6\%) foi menor do que o da silagem sem acipin (34,8\%), ocorrendo o inverso para o resíduo não degradável da PB (36,7\% contra 30,50\%) e FDN $(38,3$ e $33,5 \%)$. O valor estimado de proteína não degradável no rúmen da silagem de milho sem acipin foi menor do que o relatado por Aroeira et al. (1996), 35,8\%, entretanto, é semelhante ao citado pelo Nutrient... (1988), 31\%.

As DE da MS, da PB e da FDN da silagem de capim-elefante adicionada de acipin foram $56,6 \%, 57,5 \%$ e $78,4 \%$ maiores do que às de capim-elefante sem acipin, respectivamente.

Houve interação $(\mathrm{P}<0,05)$ de silagem e acipin para as DE da MS e da PB (Tab. 6), isto é, a inclusão de acipin resultou em diferença nas $\mathrm{DE}$ da MS e PB da silagem de capim-elefante, 39,3\% e $25,1 \%, 49,7 \%$ e $31,6 \%$, respectivamente, 
enquanto que entre silagens, a de milho sem acipin apresentou maiores DE da MS (44,8\%) e PB $(52,2 \%)$ que a silagem de capim-elefante sem acipin, $25,1 \%$ e $31,6 \%$, respectivamente.
Todavia, para a DE da FDN, não foi observada interação. A DE foi maior na presença de acipin $(35,7 \%)$ e para silagem de milho $(34,6 \%)$.

Tabela 6. Degradabilidade efetiva (DE) da matéria seca (MS), proteína bruta (PB) e fibra em detergente neutro (FDN) das silagens, para as taxas de passagem (k) de 1,$51 ; 1,08 ; 2,68$ e 2,81\%/h

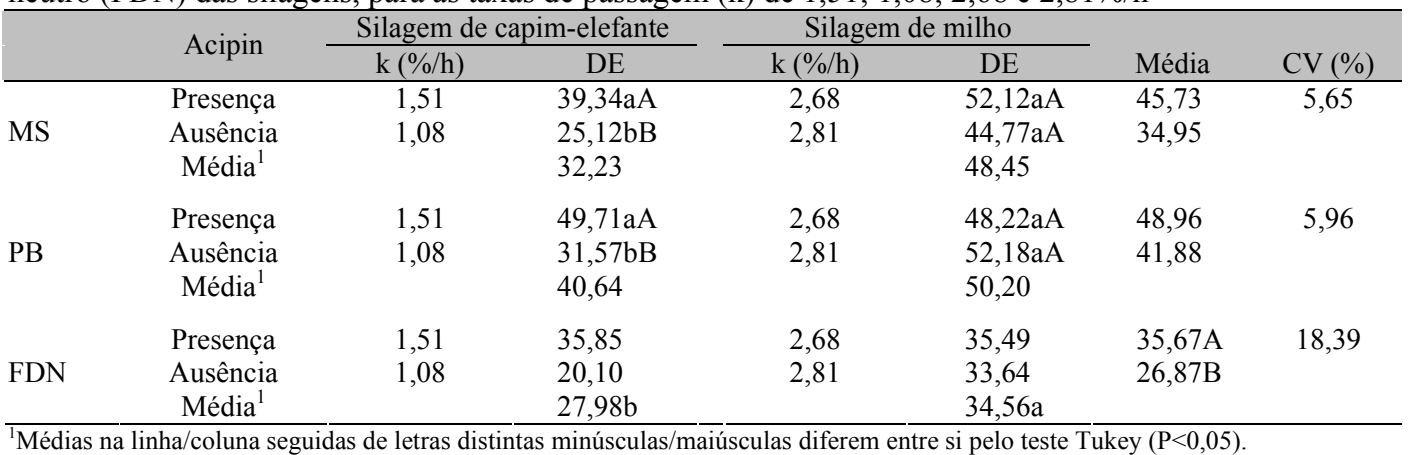

A DE da MS $(44,8 \%)$ da silagem de milho sem acipin está próxima da encontrada por Aroeira et al. (1996), 45,0\%, no entanto, a DE da PB $(52,2 \%)$ foi menor do que à relatada por esses autores $(64,2 \%)$, que utilizaram a taxa de passagem de $5 \% / \mathrm{h}$. A degradabilidade efetiva da FDN $(33,6 \%)$ foi ligeiramente maior do que a relatada por Bertipaglia et al. (1998), 32,4\%, sendo que esses autores fizeram correção pela perda de partículas quanto à FDN das amostras.

\section{CONCLUSÕES}

A presença de acipin melhorou a degradação da silagem de capim-elefante, mas não influenciou a degradação da silagem de milho. Sua adição não modificou as taxas de passagem de sólidos e líquidos ruminais, podendo ser incluída ou não às silagens sem depreciação no seu valor nutritivo. Com base no benefício que a inclusão de acipin trouxe para a degradabilidade da silagem de capim-elefante, seu uso pode ser indicado para essa silagem.

\section{REFERÊNCIAS BIBLIOGRÁFICAS}

AGRICULTURAL Research Council. The nutrient requeriments of ruminants livestock. London: Commonwealth Agricultural Bureaux,
1984. 350p.

AROEIRA, L.J.M.; LOPES, F.C.F.; DAYRELL, M.S. Degradabilidade de alguns alimentos no rúmen de vacas holandês/zebu. Rev. Bras. Zootec., v.25, p.1178-1186, 1996.

BERTIPAGLIA, L.M.A.; MELO, G.M.P.; SIQUEIRA, G.B. et al. Degradação in situ da matéria seca, proteína bruta e fibra em detergente neutro das silagens de maracujá e de híbridos de milho. In: REUNIÃO ANUAL DA SOCIEDADE BRASILEIRA DE ZOOTECNIA, 35., 1988, Botucatu. Anais..., Botucatu: SBZ, 1998. p.365.

COLUCCI, P.E.; MACLEOD, G.K.; GROVUM, W.L. et al. Digesta kinetics in sheep and cattle fed diets with different forage to concentrate ratios at high and low intakes J. Dairy Sci., v.73, p.2143-2156,1990.

CZERKAWSKI, J.W. An introduction to rumen studies. Oxford: Pergamon International Library of Science, Technology, Engineering and Social Studies, 1986. 236p.

GOMES, B.V. Influência das características químicas e fisicas das forragens sobre o consumo, degradação e cinética da digesta ruminal. 1991. 115p. Tese (Doutorado). Universidade Federal de Viçosa, Viçosa, MG.

HRISTOV, A.N.; BRODERICK, G.A. Syntesis of microbial protein in ruminally cannulated 
cows fed alfafa silage, alfafa hay, or corn silage. J. Dairy Sci., v.79, p.1627-1637, 1996.

KIMURA, F.T.; MILLER, V.L. Improved determination of chromic oxide in cow feed and feces. J. Agric. Food Chem., v.5, p.216, 1967.

MARTINS, A.S.; ZEOULA, L. M.; PRADO, I. N. et al. Degradação ruminal in situ da matéria seca e proteína bruta das silagens de milho e sorgo e de alguns alimentos concentrados. Rev. Bras. Zootec., v.28, p.1109-1117, 1999.

McDONALD, P.; HENDERSON, A.R.; HERON, S.J. The biochemistry of silage. 2.ed. Marlow, Chalcombe Publications. 1991. 207p.

MEHREZ, A.Z.; ØRSKOV, E.R. A study of the estimation of protein degradability in the rumen. J. Agric. Sci., v.88, p.654-660, 1977.

MERTENS, D.R. Predicting intake and digestibility using mathematical models of ruminal function. J. Anim. Sci., v.64, p.15481558, 1987.

NUSSIO, L.G. Milho e sorgo para a produção de silagem. In: PEIXOTO, A.M.; MOURA, J.C; FARIA, V.P. (Eds.). Volumosos para bovinos. 2.ed. Piracicaba: Fealq, 1995. P.75-178.

NUTRIENT requirements of dairy cattle. 6.ed. Washington: NRC, 1988. 157p.

ØRSKOV, E.R.; McDONALD, I. The estimation of protein degradability in the rumen from incubation measurements of feed in weighted according to rate passage. J. Agric. Sci., v.92, p.499-503, 1979.
PURAC 1998. Circular técnica. Campos dos Goytacazes- RJ. 56p.

ROSSI JÚNIOR, P.; SILVA, A.G.; WANDERLEY, R.C. et al. Degradabilidade ruminal da matéria seca e da fração protéica da silagem de milho, de farelo de soja e do sorgo grão, em bovinos da raça nelore. Comparação com dados obtidos pelo CNCPS. Rev. Bras. Zootec., v.26, p.599-607, 1997.

SILVA, D.J. Análise de alimentos (métodos químicos e biológicos). Viçosa: Imprensa Universitária, 1990. 165p.

TOSI, P.; MATTOS, W.R.S.; TOSI, H. et al. Avaliação do capim-elefante (Pennisetum purpureum, Schum) cultivar taiwan A-148, ensilado com diferentes técnicas de redução de umidade. Rev. Bras. Zootec., v.28, p.947-954, 1999.

UDÉN, P.; COLUCCI, P.E.; VAN SOEST, P.J. Investigation of chromium, cerium and cobalt as markers in digesta. Rate of passage studies. $J$. Sci. Food Agric., v.31, p.625-632, 1980.

VILELA, D. Aditivos para silagem de plantas de clima tropical. Aditivos na produção de ruminantes. In: REUNIÃO ANUAL DA SOCIEDADE BRASILEIRA DE ZOOTECNIA, 35., 1998, Botucatu. Anais..., Botucatu: SBZ, 1998. P.73.

WALDO, D.R.; JORGENSEN, N.A. Forages for high animal production: nutritional factors and effects of conservation. J. Dairy Sci., v.64, p.1207-1229, 1981. 